\title{
Prostate cancer risk group is associated with other-cause mortality in men with localized prostate cancer
}

Rehana Rasul, MA ${ }^{1}$; Anne Golden, $\mathrm{PhD}^{1}$; Michael A. Feuerstein, $\mathrm{MD}^{2}$

${ }^{1}$ Feinstein Institutes for Medical Research, Department of Occupational Medicine, Epidemiology and Prevention, Zucker School of Medicine at Hofstra/Northwell, Hempstead, New York; ${ }^{2}$ Lenox Hill Hospital, Department of Urology, Zucker School of Medicine at Hofstra/Northwell, Hempstead, New York

Cite as: Can Urol Assoc J 2020 May 12; Epub ahead of print. http://dx.doi.org/10.5489/cuaj.6324

Published online May 12, 2020

$* * *$

Abstract

Introduction: Informed decision-making in localized prostate cancer must consider the natural history of the disease, risks of treatment, and the competing risks from other causes. Other-cause mortality has often been associated with comorbidity or treatment-related side effects. We aimed to examine the association between prostate cancer aggressiveness and other cause mortality. Methods: Using the Surveillance, Epidemiology, and End Results' (SEER)18 registries, patients diagnosed with localized prostate cancer between 2004 and 2015 were identified. Patients were categorized into low-, intermediate- and high-risk groups. Vital status, death due to prostate cancer and death due to other causes were based on death certificate information. Survival analyses were performed to assess the association between prostate cancer risk group and mortality while adjusting for demographic variables, year of diagnosis, and initial therapy. Results: A total of 464653 patients were identified with a median followup of 5.4 years. Cardiovascular disease was the most common cause of mortality during the study period. Compared to low-risk patients, intermediate- and high-risk patients had a higher risk of mortality from other cancers, from cardiovascular disease, and from other causes of death regardless of initial treatment. Men who underwent surgery as initial therapy had lower cumulative mortality rates compared to those with radiation as their initial therapy.

Conclusions: Intermediate- and high-risk prostate cancers are associated with higher risk of other-cause mortality. This appears to be independent of treatment type and may not be solely explained by comorbidity status. Further studies controlling for comorbidity and treatment burden should be explored. 


\section{Introduction}

In 2019, there will be an estimated 174,000 new cases of prostate cancer diagnosed in the United States. ${ }^{1}$ Approximately eighty percent of these patients will be diagnosed with localized disease with a 5-year prostate cancer relative-survival rate of greater than 99 percent. However, prostate cancer remains the second leading cause of cancer-related death. For predicting prostate-cancer mortality (PCM) and guiding treatment decisions, risk classifications using stage, grade and PSA have been established and routinely integrated into clinical practice. ${ }^{2}$ There is a clear and definite association between higher risk disease and PCM.

Predicting other-cause mortality (OCM) in men with prostate cancer has been more elusive. Currently, the NCCN guidelines recommend predicting individual life-expectancy based on life insurance tables and adding or subtracting 50 percent if the patient is estimated to be in the highest or lowest quartile of health status. ${ }^{3}$ Previous authors have devised nomograms and other tools using patient comorbidities to more accurately predict OCM. ${ }^{4,5}$ Other research has focused on the relationship between prostate cancer treatment and OCM, demonstrating that perhaps there is a treatment-related effect on OCM. ${ }^{6}$

To our knowledge, there has been a paucity of research examining the association between prostate cancer risk classification and OCM. This could aid pre-treatment nomograms to guide treatment decisions or further elucidate risks of treatment. The objective of this study was to report the association between prostate cancer risk classification and OCM using a nationwide cancer database.

\section{Methods}

\section{Data source}

Data were extracted from the Surveillance, Epidemiology, and End Results (SEER) 18 Registries Custom Data Release April, 2018, that included supplemental data fields for radiation therapy and chemotherapy for the November, 2017, submission, using SEER*Stat 8.3.5 software. . SEER is sponsored by the National Cancer Institute to maintain and distribute cancer incidence and survival data from population-based cancer registries representing approximately 34 percent of the U.S. population. The SEER registries collect information on site and extent of disease, first course of cancer-directed therapy and socio-demographic characteristics, with active followup for date and cause of death.

\section{Cohort}

All primary prostate cancer patients diagnosed from 2004 to 2015 with neither known regional lymph node involvement nor distant site(s) of metastatic involvement at time of diagnosis were identified and vital status was determined through December 2015. Cases were excluded if they had unknown previous cancer history or unknown cause of death, a diagnosis determined from autopsy or death, survival time less than a month after diagnosis, prostate cancer with stage IV or unknown, or whose prostate cancer risk group could not be classified. . 


\section{Outcomes}

Clinical collaborative staging (CS) characteristics related to the prostate cancer diagnosis were extracted from SEER data including AJCC 6-7 ${ }^{\text {th }}$ Edition TNM staging, tumor grade, Gleason's Score (SEER CS Site-Specific Factors 8 and 10), and prostate specific antigen (PSA) at diagnosis (Supplementary Table 1). . SEER assigns PSA a value of 0.1 for measurements 0.1 or less and a value of 98.0 for measurements 98.0 or greater. . To be consistent with the 2004-2009 SEER Gleason score definition, cases diagnosed from 2010-2015 were assigned the Gleason score from pathology samples from prostatectomy if both surgical and biopsy or transurethral resection of the prostate (TURP) samples were scored. . TNM staging was classified as T0T2/N0/M0 or T3/N0/M0. For men with stage T2 NOS, Gleason score and PSA were used to classify risk group. Prostate cancer risk group was defined using the D'Amico classification system $^{2}$ : High risk (PSA $>20 \mathrm{ng} / \mathrm{ml}$ or Gleason $>7$ or TNM stage T3); Intermediate risk (10 $\leq \mathrm{PSA} \leq 20 \mathrm{ng} / \mathrm{ml}$ or Gleason=7 or T2b/T2c); Low risk (PSA $<10 \mathrm{ng} / \mathrm{ml}$ and Gleason $<7$ and $\mathrm{T} 1$ T2a); or unknown (none of the previous). ${ }^{3}$ Men whose risk group was unknown due to missing PSA and Gleason score values were excluded $(n=38,069 ; 7.6 \%$ of 502,722 men with primary localized prostate cancer).

Other study variables were extracted from SEER, including age at diagnosis, race, marital status, census tract poverty indicator, geographic region of SEER registry and initial prostate cancer therapy (radiation or surgery). . In SEER, radiation and surgery variables are underreported and no indication of therapy should be interpreted as no/unknown. . In SEER, a variable for chemotherapy as initial therapy is limited to yes or no/unknown, therefore important treatment information such as use of concurrent androgen deprivation with radiation is not available.

Survival time was defined as the difference in months between the date of diagnosis of prostate cancer and the date of death reported to SEER, the date last known to be alive, or December, 2015, whichever was earliest. . Vital status (categorized as alive or dead), death due to a specific cancer, and death due to other non-cancer cause were based on death certificate information reported to SEER and SEER's definition of cause of death. Deaths were categorized as PCM and OCM. The latter was further subdivided into other non-prostate cancer mortality (non-PCM), cardiovascular mortality (CVM) or other causes.

\section{Statistical analysis}

The frequency and percent of categorical study variables were compared by prostate cancer risk group using Chi-square tests. . For continuous variables, mean and standard deviation (SD) or median and interquartile range (IQR) were reported and differences were assessed using Kruskal-Wallis tests.

Survival analyses were performed to assess the association between prostate cancer risk group and mortality outcomes (overall mortality, PCM, non-PCM, CVM, and other causes), while adjusting for confounders (demographic variables, year of prostate cancer diagnosis, and initial therapy). Men alive at time of last follow-up or December 2015 were censored. . For the 
outcome of overall mortality, a Cox proportional hazards model was used. For cause-specific mortality, separate Fine and Gray competing risks models were used which take into account the potential for death due to other causes. . Models were stratified by initial therapy because this variable did not exhibit proportional hazards over time. For the Cox model and Fine and Gray models, adjusted hazard ratios and adjusted sub-distribution hazard ratios were reported, respectively. Given the large sample size, results should be interpreted using confidence intervals and effect sizes to evaluate clinical relevance. Analyses were conducted using SAS software, version 9.4 (SAS Institute, Cary, NC, USA).

\section{Results}

The study cohort consisted of 464,653 men diagnosed with localized prostate cancer from 20042015. Median years of follow-up after prostate cancer diagnosis was 5.4 years (IQR=2.9-8.3). . Patient characteristics are shown in Table 1. Patients with high risk prostate cancer were older than intermediate and low risk patients. Intermediate risk patients were more likely to have prostatectomy as their initial therapy compared to high risk patients. . Low risk patients were more likely to be treated with radiation compared to intermediate and high-risk patients.

By the end of the study period, the cumulative mortality rate from any cause, adjusted for the population at risk at each time point, was $31.2 \%(95 \% \mathrm{CI}=30.8 \%-31.5 \%)$. Table 2 shows the distribution of cause of death. . CVM and other-causes were the most common causes of death $(22.9 \%$ and $39.1 \%$ of all deaths, respectively). . Prostate cancer was the most common cause of death from cancer ( $16.9 \%$ of all deaths, $44.6 \%$ of cancer deaths). . Miscellaneous malignant cancer $(10.3 \%$ of all deaths, $27.2 \%$ of cancer deaths), lung cancer $(6.5 \%$ of all deaths, $17.2 \%$ of cancer deaths), and pancreatic cancer ( $2.0 \%$ of all deaths, $5.3 \%$ of cancer deaths) comprised the majority of cancer-related deaths from non-prostate cancers. .

Table 3 presents hazard ratios for overall and cause-specific mortality by prostate cancer risk group, adjusted for age, race, marital status, poverty indicator, geographic region, year of diagnosis and initial therapy. Men with prostate cancer classified as high risk $(\mathrm{HR}=2.38,95 \%$ $\mathrm{CI}=2.33,2.43)$ or intermediate risk $(\mathrm{HR}=1.47,95 \% \mathrm{CI}=1.44,1.50)$ were more likely to die from any cause during the study period compared to those with low risk cancer. The impact of risk group on cause-specific mortality was examined for PCM, non-PCM CVM and all other causes. As expected, men in the high risk group had markedly increased risk of PCM compared to low risk patients $(\mathrm{HR}=13.70,95 \% \mathrm{CI}=12.69,14.79)$; the risk of $\mathrm{PCM}$ was significantly increased for intermediate risk patients as well $(\mathrm{HR}=3.03,95 \% \mathrm{CI}=2.79,3.28)$. High risk patients also had the highest risks of death for non-PCM, CVM, and other causes; they had significantly greater risks for each specific cause of death that comprised OCM with the exception of Alzheimer's disease (data not shown).

Several patient characteristics examined in addition to prostate cancer risk group were associated with increased mortality (Table 3). While blacks did not have higher risk for PCM compared to whites, modest but statistically significant higher risks were seen for all other causes of death. Men of other races had significantly lower risk of dying compared to whites for 
all causes of death. Unmarried men and those living in areas with greater poverty were more likely to die during the study follow-up period.

Figure 1 examines the impact over time that initial prostate cancer therapy and risk group had on overall mortality and on PCM and OCM. Men who underwent a prostatectomy had lower cumulative mortality rates compared to those with radiation as their initial therapy, irrespective of prostate cancer risk group. Within each therapy group, high risk patients had higher cumulative mortality rates than intermediate or low risk patients. This data should be interpreted with caution, as use of concurrent or subsequent androgen deprivation therapy is unknown.

\section{Discussion}

Treatment decisions for patients with localized prostate cancer must consider the long natural history of the disease, risks of treatment and the competing risks of mortality between prostate cancer and other causes. Two large, randomized trials conducted in the PSA-era demonstrated the protracted course of localized prostate cancer and the minimal impact of radical treatment (surgery or radiation) on overall survival. ${ }^{8,}{ }^{9}$ While these studies added further support for active surveillance in low risk patients, the risk of PCM is more significant in patients with high grade disease (Gleason score 8-10), who have a 15-year PCM of 22-27\%. ${ }^{10}$

To help clinicians and patients, prior authors have developed nomograms that incorporate age, comorbidity and primary treatment to predict PCM and OCM. ${ }^{11,12}$ Other authors have focused on developing models that predict OCM using comorbidity. ${ }^{4,5}$ For example, in the Prostate Cancer Outcomes Study, among 3,183 men diagnosed with non-metastatic prostate cancer in 1994-1995, cumulative incidence curves for other-cause mortality demonstrate a direct relationship between higher OCM and risk group. ${ }^{4}$ In a SEER-Medicare study of patients undergoing surgery or observation for localized prostate cancer, higher stage was significantly associated with OCM on multivariate analysis. ${ }^{11}$ Similarly, in a multicenter study of patients undergoing surgery or radiation, multivariable analysis showed overall survival was associated with PSA, biopsy Gleason score and clinical stage. ${ }^{13}$

In the current study, in addition to the expected significant increase in PCM, men classified as high risk were also more likely to die from other causes, including a $39 \%$ increase in other cancers, $53 \%$ increase in diseases of the heart and $48 \%$ increase in other conditions. . These increases are adjusted for known socio-demographic risk factors associated with CVM and OCM that were included in the models but other alternative explanations, including behaviors such as smoking and clinical factors including comorbidities, and treatment effects could not be ruled out due to limitations in the SEER dataset. .

One possible explanation for our findings is that patients with more comorbidities are diagnosed with more advanced disease due to less frequent or later screening. We would then expect comorbidity to be associated with PCM. However, two prior studies found no relationship between number of comorbidities and PCM in men with localized prostate cancer. ${ }^{4,12}$

Another explanation is that the type or burden of treatment may be correlated with more advanced disease and higher risk of OCM. In patients with localized prostate cancer, several 
studies have demonstrated an association with radiation therapy and androgen deprivation therapy with increased OCM compared to surgery. ${ }^{12-15}$ While these studies tried to control for age and comorbidities, it is likely that this association is at least in part due to confounding factors aside from treatment. In a large, population-based cohort, there was no association between androgen deprivation therapy and other-cause mortality. ${ }^{16}$ In the current study, the relationship between risk group and OCM was similar between patients initially treated with surgery and those treated with radiation. Unfortunately, due to limitations of this data, the use and impact of androgen deprivation therapy is unknown. Further analysis using a more granular dataset such as SEER-linked to Medicare could elucidate the impact of androgen deprivation therapy but would be limited to men 65 years of age and older.

Other limitations of using SEER data, particularly for urologic oncology, are well described. ${ }^{7}$ Misclassification of cause of death could impact our primary outcome of OCM, but SEER definitions for cause of death have previously been demonstrated to be accurate. ${ }^{17}$ In this study, diagnosis date for prostate cancer ranged from 2004 to 2015; patients had unequal follow up time during the study period and the median follow-up for this study was about 5 years. . Therefore, fewer men were available in the analysis for later survival times due to their later year of diagnosis. We accounted for this by including year of diagnosis in the models; furthermore, analyses restricted to men diagnosed in 2004 who had the longest potential follow-up time (up to 11 years) showed very similar patterns for causes of death. Secondly, important known risk factors for overall and cause-specific mortality are not recorded in the SEER data. Important lifestyle and clinical factors such as smoking, alcohol intake, diet, family history, comorbidities, and unmeasured treatment measures including hormonal therapy cannot be ruled out as explanatory variables for the observed associations with prostate cancer risk group.

In summary, we found a direct association between higher prostate cancer risk group and other- cause mortality. Validation of our findings in a cohort of patients with known comorbidities and more granular treatment data should be explored. Prostate cancer risk group should be considered in development of models predicting OCM and overall mortality. The impact of treatment burden and OCM should be further evaluated. These findings may help clinicians and patients decide on observation versus treatment for localized prostate cancer. 


\section{References}

1. Siegel RL, Miller KD, Jemal A. Cancer statistics, 2019. CA: a cancer journal for clinicians. 2019 Jan;69(1):7-34.

2. D'Amico AV, Whittington R, Malkowicz SB, Schultz D, Blank K, Broderick GA, et al. Biochemical outcome after radical prostatectomy, external beam radiation therapy, or interstitial radiation therapy for clinically localized prostate cancer. Jama. 1998 Sep 16;280(11):969-74.

3. NCCN Clinical Practice Guidline: Prostate Cancer 2019 [cited 2019 February 19, 2019]. 4.2018:[Available from: https://http://www.nccn.org/professionals/physician_gls/pdf/prostate.pdf.

4. Daskivich TJ, Fan KH, Koyama T, Albertsen PC, Goodman M, Hamilton AS, et al. Prediction of long-term other-cause mortality in men with early-stage prostate cancer: results from the Prostate Cancer Outcomes Study. Urology. 2015 Jan;85(1):92-100.

5. Kent M, Penson DF, Albertsen PC, Goodman M, Hamilton AS, Stanford JL, et al. Successful external validation of a model to predict other cause mortality in localized prostate cancer. BMC medicine. 2016 Feb 9;14:25. P

6. Cooperberg MR, Broering JM, Carroll PR. Risk assessment for prostate cancer metastasis and mortality at the time of diagnosis. Journal of the National Cancer Institute. 2009 Jun 16;101(12):878-87.

7. Scosyrev E, Messing J, Noyes K, Veazie P, Messing E. Surveillance Epidemiology and End Results (SEER) program and population-based research in urologic oncology: an overview. Urologic oncology. 2012 Mar-Apr;30(2):126-32.

8. Hamdy FC, Donovan JL, Lane JA, Mason M, Metcalfe C, Holding P, et al. 10-Year Outcomes after Monitoring, Surgery, or Radiotherapy for Localized Prostate Cancer. The New England journal of medicine. 2016 Oct 13;375(15):1415-24.

9. Wilt TJ, Jones KM, Barry MJ, Andriole GL, Culkin D, Wheeler T, et al. Follow-up of Prostatectomy versus Observation for Early Prostate Cancer. The New England journal of medicine. 2017 Jul 13;377(2):132-42.

10. Lu-Yao GL, Albertsen PC, Moore DF, Lin Y, DiPaola RS, Yao SL. Fifteen-year Outcomes Following Conservative Management Among Men Aged 65 Years or Older with Localized Prostate Cancer. European urology. 2015 Nov;68(5):805-11.

11. Abdollah F, Sun M, Schmitges J, Tian Z, Jeldres C, Briganti A, et al. Cancer-specific and other-cause mortality after radical prostatectomy versus observation in patients with prostate cancer: competing-risks analysis of a large North American population-based cohort. European urology. 2011 Nov;60(5):920-30.

12. Kutikov A, Cooperberg MR, Paciorek AT, Uzzo RG, Carroll PR, Boorjian SA. Evaluating prostate cancer mortality and competing risks of death in patients with localized prostate cancer using a comprehensive nomogram. Prostate cancer and prostatic diseases. 2012 Dec;15(4):374-9.

13. Kibel AS, Ciezki JP, Klein EA, Reddy CA, Lubahn JD, Haslag-Minoff J, et al. Survival among men with clinically localized prostate cancer treated with radical prostatectomy or radiation therapy in the prostate specific antigen era. The Journal of urology. 2012 Apr;187(4):1259-65. 
14. Cooperberg MR, Vickers AJ, Broering JM, Carroll PR. Comparative risk-adjusted mortality outcomes after primary surgery, radiotherapy, or androgen-deprivation therapy for localized prostate cancer. Cancer. 2010 Nov 15;116(22):5226-34.

15. Wallis CJD, Satkunasivam R, Herschorn S, Law C, Seth A, Kodama RT, et al. Association Between Primary Local Treatment and Non-prostate Cancer Mortality in Men With Nonmetastatic Prostate Cancer. Urology. 2018 Apr;114:147-54.

16. Wallis CJD, Satkunasivam R, Herschorn S, Law C, Seth A, Kodama RT, et al. Null association between androgen-deprivation therapy and nonprostate cancer mortality among older men with nonmetastatic prostate cancer. Urologic oncology. 2018 May;36(5):241 e1- e6.

17. Penson DF, Albertsen PC, Nelson PS, Barry M, Stanford JL. Determining cause of death in prostate cancer: are death certificates valid? Journal of the National Cancer Institute. 2001 Dec 5;93(23):1822-3.

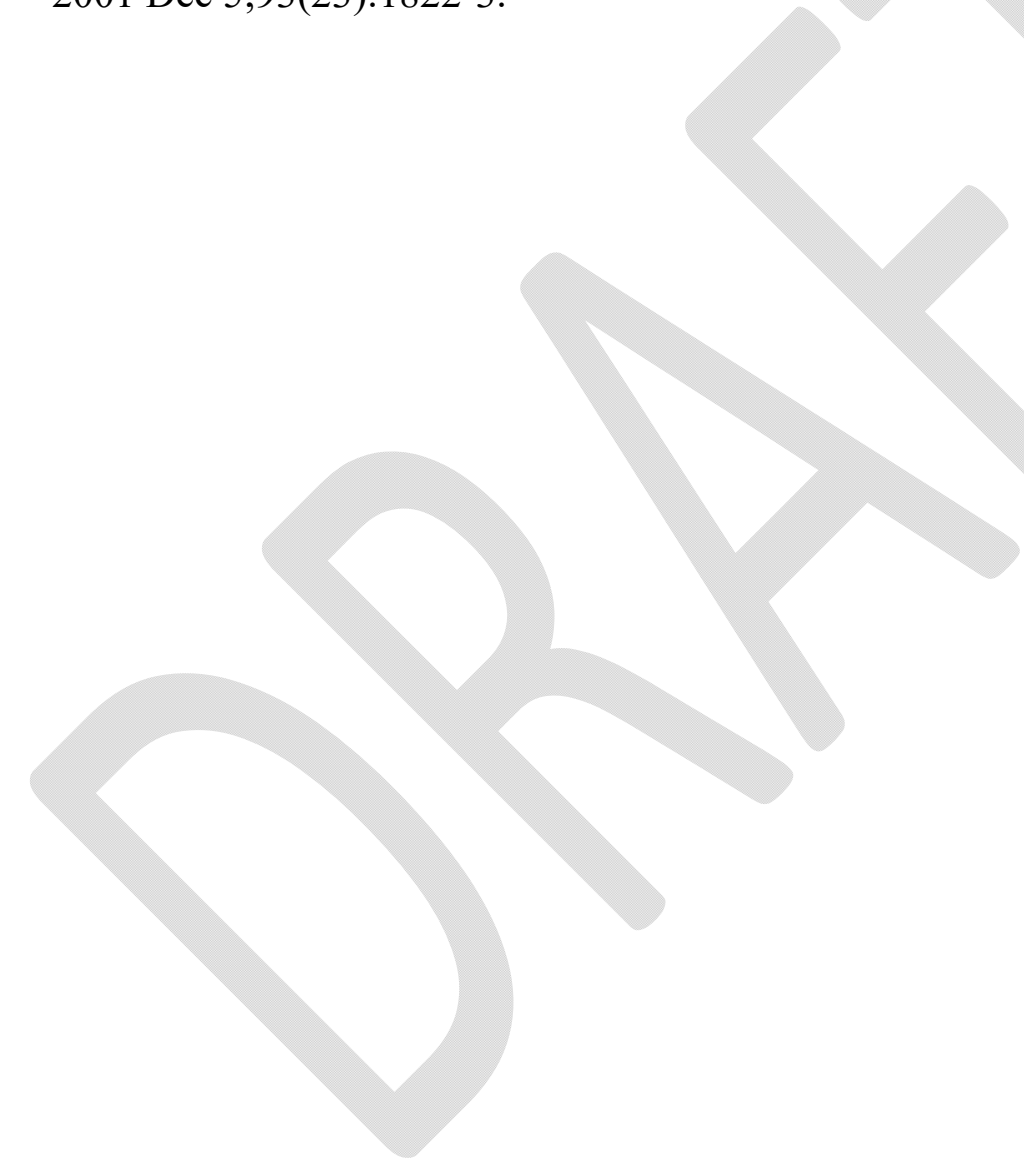




\section{Figures and Tables}

Fig. 1. Adjusted estimations of cumulative incidence functions for overall mortality, prostate cancer mortality (PCM) and other-cause mortality (OCM) in men with localized prostate cancer, by risk group and initial therapy for prostate cancer, Surveillance, Epidemiology, and End Results (SEER) 2004-2015.

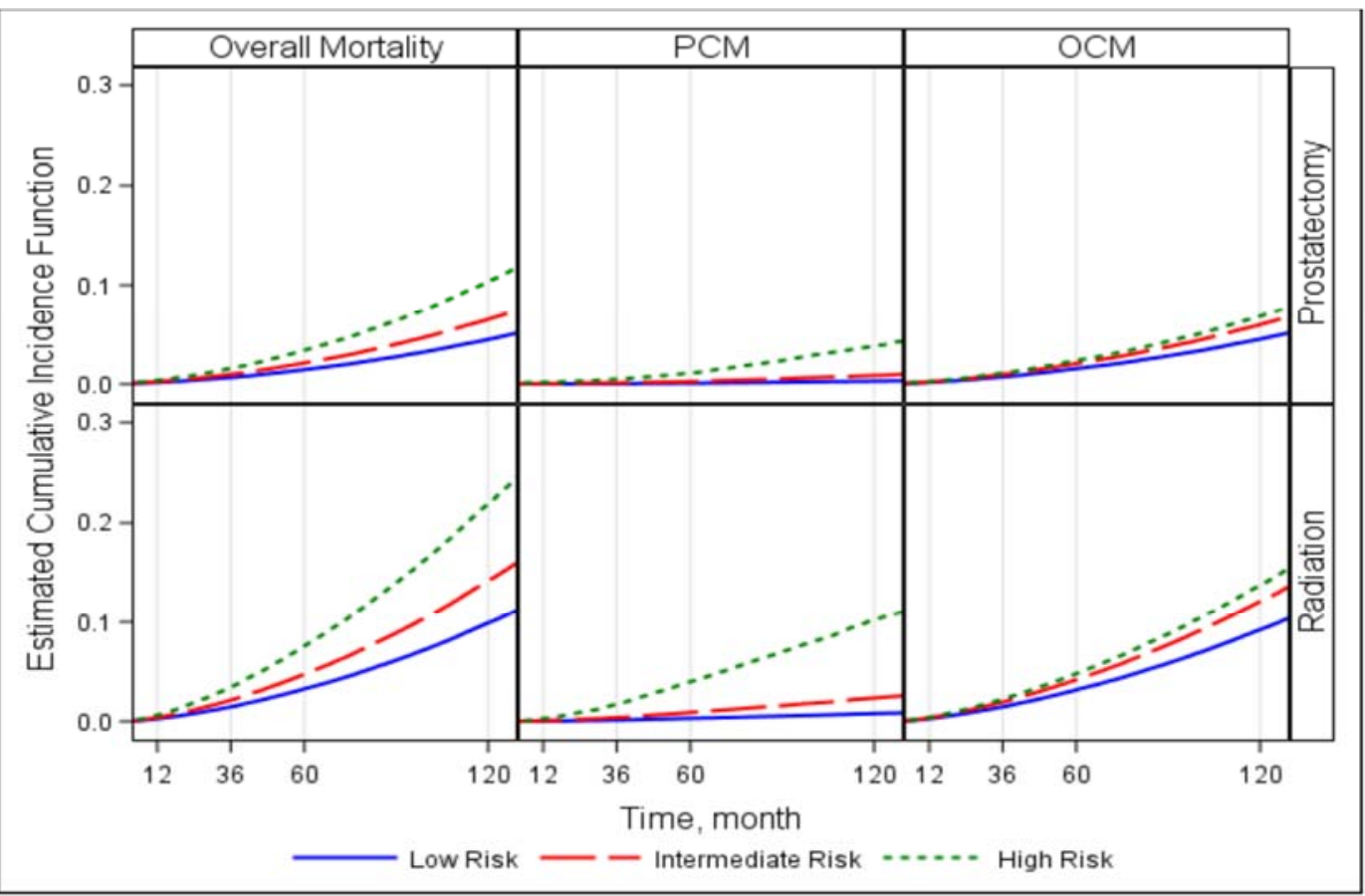




\begin{tabular}{|c|c|c|c|c|c|c|c|c|}
\hline Characteristic & \multicolumn{2}{|c|}{$\begin{array}{c}\text { Overall } \\
(\mathrm{N}=464653)\end{array}$} & \multicolumn{2}{|c|}{$\begin{array}{c}\text { Low-risk } \\
(n=122398,26.3 \%)\end{array}$} & \multicolumn{2}{|c|}{$\begin{array}{c}\text { Intermediate-risk } \\
(n=229996,49.5 \%)\end{array}$} & \multicolumn{2}{|c|}{$\begin{array}{c}\text { High-risk } \\
(\mathrm{n}=112259,24.2 \%)\end{array}$} \\
\hline \multicolumn{9}{|l|}{ Age group (years) } \\
\hline$<55$ & 52020 & 11.1 & 13526 & 11.1 & 29341 & 12.8 & 9153 & 8.2 \\
\hline $55-64$ & 163020 & 34.7 & 45100 & 36.9 & 84096 & 36.6 & 33824 & 30.1 \\
\hline$\geq 85$ & 8658 & 1.8 & 783 & 0.6 & 3130 & 1.4 & 4745 & 4.2 \\
\hline \multicolumn{9}{|l|}{ Race } \\
\hline White & 360800 & 76.8 & 96580 & 78.9 & 179012 & 77.8 & 85208 & 75.9 \\
\hline Black & 71301 & 15.2 & 17155 & 14.0 & 35976 & 15.6 & 18170 & 16.2 \\
\hline $\begin{array}{l}\text { American Indian/AK native, } \\
\text { Asian/Pacific Islander }\end{array}$ & 23682 & 5.0 & 5598 & 4.6 & 10950 & 4.8 & 7134 & 6.4 \\
\hline Q2 & 114703 & 24.4 & 29821 & 24.4 & 56769 & 24.7 & 28113 & 25.0 \\
\hline Q3 & 117071 & 24.9 & 30842 & 25.2 & 58344 & 25.4 & 27885 & 24.8 \\
\hline Q4 & 108603 & 23.1 & 28065 & 22.9 & 53259 & 23.2 & 27279 & 24.3 \\
\hline \multicolumn{9}{|l|}{ Marital status } \\
\hline Married & 319352 & 68.0 & 83172 & 68.0 & 160848 & 69.9 & 75332 & 67.1 \\
\hline Unmarried & 94483 & 20.1 & 23619 & 19.3 & 45495 & 19.8 & 25369 & 22.6 \\
\hline Unknown & 50818 & 10.8 & 15607 & 12.8 & 23653 & 10.3 & 11558 & 10.3 \\
\hline \multicolumn{9}{|l|}{$\begin{array}{l}\text { Geographic region of SEER } \\
\text { cancer registry }\end{array}$} \\
\hline West & 232085 & 49.4 & 62867 & 51.4 & 112253 & 48.8 & 56965 & 50.7 \\
\hline Central & 98571 & 21.0 & 23037 & 18.8 & 50555 & 22.0 & 24979 & 22.3 \\
\hline
\end{tabular}




\section{group and mortality}

\begin{tabular}{|c|c|c|c|c|c|c|c|c|}
\hline Year of prostate cancer diagnosis & & & & & & & & \\
\hline $2004-2005$ & 76307 & 16.3 & 22956 & 18.8 & 35653 & 15.5 & 17698 & 15.8 \\
\hline $2006-2007$ & 89093 & 19.0 & 25537 & 20.9 & 43543 & 18.9 & 20013 & 17.8 \\
\hline $2008-2009$ & 81993 & 17.5 & 20784 & 17.0 & 41927 & 18.2 & 19282 & 17.2 \\
\hline $2012-2013$ & 70074 & 14.9 & 17419 & 14.2 & 35059 & 15.2 & 17596 & 15.7 \\
\hline $2014-2015$ & 60719 & 12.9 & 13379 & 10.9 & 29849 & 13.0 & 17491 & 15.6 \\
\hline PSA level (ng/ml) & & & & 2 & 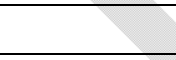 & & & \\
\hline $10-20$ & 68437 & 14.6 & 0 & 0.0 & 49492 & 23.8 & 18945 & 18.3 \\
\hline$>20$ & 34205 & 7.3 & 0 & 0.0 & 0 & 0.0 & 34205 & 33.1 \\
\hline Gleason score & & & & 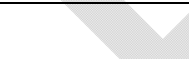 & 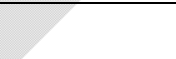 & 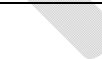 & & \\
\hline$\leq 6$ & 190683 & 40.6 & 122398 & 100.0 & 58983 & 26.2 & 9302 & 8.5 \\
\hline 7 & 203760 & 43.4 & 0 & 0.0 & 166241 & 73.8 & 37519 & 34.3 \\
\hline $8-10$ & 62701 & 13.4 & 0 & 0.0 & 0 & 0.0 & 62701 & 57.3 \\
\hline T2NOS & 85432 & 18.2 & 27472 & 22.4 & 38875 & 16.9 & 19085 & 17.0 \\
\hline T3 & 42768 & 9.1 & 0 & 0.0 & 0 & 0.0 & 42768 & 38.1 \\
\hline Initial therapy for prostate cancer & 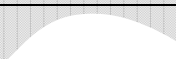 & & & V & & & & \\
\hline None & 102663 & 21.9 & 45696 & 37.3 & 35312 & 15.4 & 21655 & 19.3 \\
\hline Radiation & 160820 & 34.2 & 53054 & 43.4 & 70895 & 30.8 & 36871 & 32.8 \\
\hline Prostatectomy & 179949 & 38.3 & 16767 & 13.7 & 115359 & 50.2 & 47823 & 42.6 \\
\hline Other initial therapy & 21221 & 4.5 & 6881 & 5.6 & 8430 & 3.7 & 5910 & 5.3 \\
\hline
\end{tabular}

AJCC: American Joint Committee on Cancer; PSA: prostate-specific antigen; SEER: Surveillance, Epidemiology, and End Results. 
Association between prostate cancer risk group and mortality

\begin{tabular}{|l|c|c|}
\hline \multicolumn{3}{|l|}{ Table 2. Leading causes of death from cancer and other conditions in men with } \\
localized prostate cancer, SEER 2004-2015 \\
\hline Cause of death & Number of deaths & \% of deaths \\
\hline All causes & $\mathbf{6 4 7 9 4}$ & $\mathbf{3 7 . 9}$ \\
\hline Cancers & $\mathbf{2 4 5 8 2}$ & 16.9 \\
\hline Prostate cancer & 10967 & 10.3 \\
\hline Miscellaneous malignant cancer & 6680 & 6.5 \\
\hline Lung or bronchus cancer & 4236 & 2.0 \\
\hline Pancreas cancer & 1309 & 1.4 \\
\hline Colon (excluding rectum) & 882 & 0.8 \\
\hline Urinary bladder & 508 & $\mathbf{6 2 . 1}$ \\
\hline Non-cancer causes & $\mathbf{4 0 2 1 2}$ & 22.9 \\
\hline Cardiovascular disease & 14852 & 20.4 \\
\hline Any other non-cancer & 13213 & 5.1 \\
\hline COPD and allied conditions & 3303 & 4.3 \\
\hline Cerebrovascular diseases & 2779 & 2.6 \\
\hline Diabetes mellitus & 1679 & 2.6 \\
\hline Accidents and adverse effects & 1664 & 2.4 \\
\hline Alzheimer's disease & 1562 & 1.8 \\
\hline Pneumonia and influenza & 1160 & \\
\hline
\end{tabular}

SEER: Surveillance, Epidemiology, and End Results. 


\begin{tabular}{|c|c|c|c|c|c|}
\hline \multirow[b]{2}{*}{ Category } & \multirow{2}{*}{$\begin{array}{c}\text { Overall } \\
\text { mortality }\end{array}$} & \multirow[b]{2}{*}{ PCM } & \multicolumn{3}{|c|}{ OCM } \\
\hline & & & Non-PCM & CVM & Other causes \\
\hline \multicolumn{6}{|c|}{ Prostate cancer risk group (ref = low-risk) } \\
\hline High-risk & $\begin{array}{c}2.38 \\
(2.33,2.43)\end{array}$ & $\begin{array}{c}13.71 \\
(12.70,14.80) \\
\end{array}$ & $\begin{array}{c}1.39 \\
(1.32,1.46)\end{array}$ & $1.53(1.46,1.60)$ & $\begin{array}{c}1.48 \\
(1.43,1.53)\end{array}$ \\
\hline $\begin{array}{l}\text { Intermediate- } \\
\text { risk }\end{array}$ & $\begin{array}{c}1.47 \\
(1.44,1.50)\end{array}$ & $\begin{array}{c}3.03 \\
(2.80,3.29) \\
\end{array}$ & $\begin{array}{c}1.25 \\
(1.20,1.31)\end{array}$ & $1.35(1.29,1.41)$ & $\begin{array}{c}1.30 \\
(1.26,1.34)\end{array}$ \\
\hline \multicolumn{6}{|c|}{ Age group (ref $=<55$ years) } \\
\hline $55-64$ years & $\begin{array}{c}1.61 \\
(1.53,1.69)\end{array}$ & $\begin{array}{c}1.03 \\
(0.94,1.13) \\
\end{array}$ & $\begin{array}{c}2.11 \\
(1.91,2.33)\end{array}$ & $1.78(1.60,1.99)$ & $\begin{array}{c}1.56 \\
(1.44,1.69) \\
\end{array}$ \\
\hline $65-74$ years & $\begin{array}{c}2.85 \\
(2.72,2.99) \\
\end{array}$ & $\begin{array}{c}1.14 \\
(1.04,1.26)\end{array}$ & $\begin{array}{c}3.63 \\
(3.28,4.01) \\
\end{array}$ & $3.22(2.90,3.58)$ & $\begin{array}{c}3.17 \\
(2.93,3.43)\end{array}$ \\
\hline $75-84$ years & $\begin{array}{c}5.34 \\
(5.09,5.60)\end{array}$ & $\begin{array}{c}1.50 \\
(1.36,1.65)\end{array}$ & $\begin{array}{c}4.70 \\
(4.23,5.22)\end{array}$ & $6.24(5.60,6.95)$ & $\begin{array}{c}6.46 \\
(5.96,7.00)\end{array}$ \\
\hline$\geq 85$ years & $\begin{array}{c}11.02 \\
(10.44,11.63) \\
\end{array}$ & $\begin{array}{c}2.12 \\
(1.89,2.36) \\
\end{array}$ & $\begin{array}{c}4.26 \\
(3.72,4.89) \\
\end{array}$ & $\begin{array}{c}12.24 \\
(10.87,13.78) \\
\end{array}$ & $\begin{array}{c}10.90 \\
(9.96,11.93) \\
\end{array}$ \\
\hline \multicolumn{6}{|c|}{ Race (ref $=$ White) } \\
\hline Black & $\begin{array}{c}1.16 \\
(1.14,1.19)\end{array}$ & $\begin{array}{c}1.02 \\
(0.97,1.07)\end{array}$ & $\begin{array}{c}1.13 \\
(1.08,1.19)\end{array}$ & $1.26(1.21,1.32)$ & $\begin{array}{c}1.16 \\
(1.12,1.20)\end{array}$ \\
\hline $\begin{array}{l}\text { American } \\
\text { Indian/ } \\
\text { AK Native, } \\
\text { Asian/Pacific } \\
\text { Islander, and } \\
\text { unknown }\end{array}$ & $\begin{array}{c}0.62 \\
(0.60,0.64)\end{array}$ & $\begin{array}{c}0.59 \\
(0.54,0.65)\end{array}$ & $\begin{array}{c}0.74 \\
(0.68,0.80)\end{array}$ & $\begin{array}{c}0.61 \\
(0.56,0.66)\end{array}$ & $\begin{array}{c}0.69 \\
(0.65,0.73)\end{array}$ \\
\hline \multicolumn{6}{|c|}{ Marital status (ref = Married) } \\
\hline Unmarried & $\begin{array}{c}1.37 \\
(1.35,1.40) \\
\end{array}$ & $\begin{array}{c}1.18 \\
(1.12,1.23) \\
\end{array}$ & $\begin{array}{c}1.17 \\
(1.12,1.22) \\
\end{array}$ & $1.44(1.39,1.50)$ & $\begin{array}{c}1.37 \\
(1.33,1.41) \\
\end{array}$ \\
\hline Unknown & $\begin{array}{c}1.09(1.06, \\
1.12) \\
\end{array}$ & $\begin{array}{c}1.10(1.03 \\
1.16) \\
\end{array}$ & $\begin{array}{c}0.95(0.89 \\
1.00) \\
\end{array}$ & $1.12(1.06,1.18)$ & $\begin{array}{c}1.12(1.08, \\
1.16)\end{array}$ \\
\hline \multicolumn{6}{|c|}{ Poverty $($ ref $=$ Q1) } \\
\hline Q2 & $\begin{array}{c}1.09 \\
(1.06,1.11) \\
\end{array}$ & $\begin{array}{c}1.14 \\
(1.08,1.21) \\
\end{array}$ & $\begin{array}{c}1.07 \\
(1.02,1.12) \\
\end{array}$ & $1.06(1.01,1.11)$ & $\begin{array}{c}1.06 \\
(1.03,1.1) \\
\end{array}$ \\
\hline Q3 & $\begin{array}{c}1.14 \\
(1.11,1.16)\end{array}$ & $\begin{array}{c}1.21 \\
(1.14,1.28)\end{array}$ & $\begin{array}{c}1.08 \\
(1.03,1.13)\end{array}$ & $1.15(1.10,1.21)$ & $\begin{array}{c}1.08 \\
(1.04,1.12)\end{array}$ \\
\hline Q4 & $\begin{array}{c}1.28 \\
(1.25,1.31) \\
\end{array}$ & $\begin{array}{c}1.25 \\
(1.18,1.32)\end{array}$ & $\begin{array}{c}1.14 \\
(1.09,1.20) \\
\end{array}$ & $\begin{array}{c}1.29 \\
(1.23,1.35)\end{array}$ & $\begin{array}{c}1.26 \\
(1.22,1.31)\end{array}$ \\
\hline \multicolumn{6}{|c|}{ Region (ref $=$ West) } \\
\hline Central & $\begin{array}{c}1.18 \\
(1.16,1.21) \\
\end{array}$ & $\begin{array}{c}0.95 \\
(0.91,1.00) \\
\end{array}$ & $\begin{array}{c}1.19 \\
(1.14,1.25) \\
\end{array}$ & $1.15(1.11,1.20)$ & $\begin{array}{c}1.22 \\
(1.18,1.26) \\
\end{array}$ \\
\hline
\end{tabular}


Association between prostate cancer risk group and mortality

\begin{tabular}{|l|c|c|c|c|c|} 
East & 1.05 & 0.95 & 1.02 & $1.03(0.99,1.07)$ & 1.10 \\
& $(1.03,1.07)$ & $(0.90,0.99)$ & $(0.98,1.06)$ & & $(1.07,1.13)$ \\
\hline
\end{tabular}

Cause of death categories: CVM: cardiovascular mortality; OCM: other-cause mortality; PCM: prostate cancer mortality; SEER: Surveillance, Epidemiology, and End Results.

\begin{tabular}{|c|c|c|c|}
\hline \multicolumn{4}{|c|}{$\begin{array}{l}\text { Supplementary Table. } 1 \text {. ICD-9 and ICD-10 codes for causes of death from cancer and other conditions } \\
\text { in men with localized prostate cancer, SEER } 2004-2015 \text {. }\end{array}$} \\
\hline Cause of death & ICD-9 codes & ICD-10 codes & $\begin{array}{l}\text { SEER cause of death } \\
\text { Re-code }\end{array}$ \\
\hline \multicolumn{4}{|l|}{ Cancers } \\
\hline Prostate cancer & 185 & C61 & $54,57,61$ \\
\hline Lung or bronchus cancer & $\begin{array}{l}162.2-162.5,162.8- \\
162.9\end{array}$ & $\mathrm{C} 34$ & 39 \\
\hline Pancreas cancer & 157 & $\mathrm{C} 25$ & 33 \\
\hline Colon (excluding rectum) & $153,159.0$ & $\mathrm{C} 18, \mathrm{C} 26.0$ & 14 \\
\hline Urinary bladder & 188 & C67 & 58 \\
\hline $\begin{array}{l}\text { Miscellaneous malignant } \\
\text { cancer }\end{array}$ & \multicolumn{3}{|c|}{ Any other cancer code } \\
\hline \multicolumn{4}{|l|}{ Other causes } \\
\hline Heart disease & $\begin{array}{l}309-398,402,404 \\
410-429\end{array}$ & $\begin{array}{l}\text { 309-398, 402, 404, } \\
\quad 410-429\end{array}$ & 154 \\
\hline COPD \& allied conditions & $490-493,519.3$ & $490-496$ & 175 \\
\hline Cerebrovascular diseases & $430-438$ & $430-438$ & 160 \\
\hline Diabetes mellitus & 250 & 250 & 148 \\
\hline $\begin{array}{l}\text { Accidents \& adverse } \\
\text { effects }\end{array}$ & $800-849$ & $800-849$ & 199 \\
\hline Alzheimer's disease & $\mathrm{N} / \mathrm{A}$ & 331.0 & 151 \\
\hline Pneumonia and influenza & $470-474,480-486$ & $480-487$ & 172 \\
\hline Any other non-cancer & \multicolumn{3}{|c|}{ Any other non-cancer code } \\
\hline
\end{tabular}

SEER: Surveillance, Epidemiology, and End Results 